\title{
MARKETING A MEMORY OF THE WORLD: MAGNA CARTA AND THE EXPERIENTIAL SERVICESCAPE
}

\section{Purpose}

The aim of this paper is to analyse visitor perceptions of the Lincoln Magna Carta exhibition in the context of an experiential servicescape perspective.

\section{Design/methodology/approach}

Data comes from a questionnaire carried out with visitors to the Magna Carta exhibition in Lincoln Castle, UK. The approach was framed by the student as producer perspective that is about re-engineering the relationship between academics and undergraduate students.

\section{Findings}

Three main problems exist in terms of the servicescape. These are guidance signage, the small, dark inauspicious surroundings of the exhibition itself and the level of visitor interactivity present.

\section{Research limitations/implications}

This is only a small scale project of one Magna Carta exhibition. Research with more visitors would help to further validate the findings and conclusions of this paper and also assist in other representations of the document in other sites.

\section{Practical implications}

Suggestions are made for improvement to a number of experiential servicescape elements. These improved representations also need to be planned for adequately in the new staging of the document, when Lincoln Castle receives planned additional funds from the Heritage Lottery.

\section{Social implications}

This paper draws our attention to the fact that The Magna Carta is a shared part of a global cultural identity, where the marketing of the document represents a great privilege.

\section{Originality/value}

The experiential servicescape framework is used in an original way to critique aspects of the current exhibition and to propose new ideas for representing the Magna Carta. This paper is based on original data that makes a novel contribution to the debate regarding research and learning in higher education.

Keywords: Magna Carta , Experiential, Servicescape, Student as Producer, Heritage Marketing 


\section{INTRODUCTION: MAGNA CARTA, HERITAGE REPRESENTATIONS AND SERVICESCAPES}

It is evident that there is a continued and deep interest in all aspects of heritage, viewed as 'consumable' history (Misiura, 2006; Babour and Turnbull, 2002; McDonald 2011). An example of this phenomenon is the Magna Carta, soon to celebrate its $800^{\text {th }}$ anniversary (BBC News, 2010). Commemorative stamps, coins, major exhibitions and a possible public holiday are all planned for the anniversary. The Magna Carta is regarded by many as being the very the cornerstone of civil liberties around the globe (West, 2008; Whipps, 2008). As evidence of its significance, Magna Carta was awarded in July 2009 'Memory of the World' status by the United Nations Educational, Scientific and Cultural Organization (UNESCO.org 2010). The Memory of the World Programme aims to preserve and disseminate highly significant documentary archive collections that exist around the globe (UNESCO.org 2010). Possessing 'Memory of the World' status are such significant heritage artefacts as the Bayeux Tapestry, the diaries of Anne Frank and the writings of the South American revolutionary leader, Simón Bolívar. For UNESCO, this type of documentary heritage reflects the diversity of languages, peoples and cultures from around the planet and is the mirror of the world and its memory (UNESCO.org 2010). Now a part of the Memory of The World Programme and viewed from a political, cultural and a historical perspective, the Magna Carta is highly influential, in particular, its clause 39, which says that no one man shall be imprisoned without judgement of their peers, or by the laws of the land. This is often quoted in local, national and global debates about civil liberties, the conduct of politics and issues such as antiterrorist laws (Bennett et al, 2007).

Magna Carta's global importance has included influencing the founding documents of the United States and the United Nations Declaration of Human Rights. One of the remaining original copies of the Magna Carta, owned by Lincoln Cathedral, is kept in the City of Lincoln, UK and is on display in Lincoln Castle. Not only does the approaching $800^{\text {th }}$ anniversary of the Great Charta gives impetus and practical import to the question of how this object should be represented and interpreted, but added to this, is the fact that Lincoln Castle has recently been awarded $£ 12$ million in Heritage Lottery funding (Lincolnshire Echo 2012). This represents a major reversal of fortune compared to the situation of two years ago, when funding plans were rejected by the government (Lincolnshire Echo (2010). In dealing with the issue of representation, a key assumption of this paper is that the consumption of heritage takes place in servicescapes (Bitner, 1992; Rosenbaum and Massiah 2011). The aim here then, is to explore the results of a visitor research project on the current Magna Carta exhibition, grounding it theoretically and analytically in an experiential servicescape perspective (Chronis 2005; Arnould et al 1998). This aim involves analysing the relevance of servicescapes when representing and interpreting heritage based consumption activity. Next, a brief background to the document is provided. This is followed by a section that outlines some relevant literature relating to the management of servicescapes. Then a methodology section follows. Subsequent to this, the current exhibition is outlined, followed by an analysis of the findings of the research. Finally, implications of the research are discussed. 


\section{BACKGROUND: THE LINCOLN MAGNA CARTA}

After King John's fruitless attempts to recapture Normandy in 1214, he returned home and was exposed to opposition from those who had suffered from his rule. Barons forced John, in 1215, to firstly negotiate and then at the now famous site of Runnymede, to sign the Magna Carta. Copies of the original document were quickly made, and of these only four now survive. One is owned by Lincoln Cathedral, one by Salisbury Cathedral and two by the British library. Each of the copies is on a vellum parchment, the copies measuring approximately A3 in size, covered in faded Latin. As a physical object, the Magna Carta might not be seen as much to look at (Danziger and Gillingham 2003), but as the latter note, these eight hundred year old documents are just as famous as any you would see in either a museum or a parliament anywhere in the world. After the signing of the document and from the time of the accession of King John's son, Henry III, Magna Carta was reissued in varying forms throughout the years that followed, becoming a central part of English Law (Linebaugh 2008; Breay 2002).

Lincoln's copy of the Magna Carta lay undisturbed and unrecognised among the extensive Dean and Chapter archives until the early nineteenth century (Bennett et al 2007). In 1848, members of the Archaeological Institute visited Lincoln and recorded that the Magna Carta had been framed and was hanging in the Chapter Clerk's office. Much later, when the British Government requested that Lincoln's Magna Carta be sent to the British Pavilion at the New York World's Fair in 1939, it was because concerns were raised about its safety at a time of war. The British Government then requested that it should stay in the United States for the duration of hostilities, so it was sent to the Library of Congress in Washington, D.C. Lincoln's Magna Carta returned to the Cathedral in 1947, where it has been ever since, apart from the times it tours, which is mainly for brief periods in America.

\section{EXPERIENTIAL SERVICESCAPES}

The notion of a servicescape is generally regarded to have emerged in the work of Bitner (1992). A servicescape refers to the entire spatially bounded environment that consumers respond to. The servicescape can be viewed as the built environment (Wakefield and Blodgett 1994), in which a market place exchange is performed. Bitner (1992) consolidated the various extant environmental stimuli into three dimensions, these being ambient conditions, spatial layoutlfunctionality and finally, signs, symbols and artefacts. The ambient dimension covers controllable observable stimuli, for instance temperature, air quality, noise, music, visual factors like colour, shape and cleanliness (Bitner 1992). The second factor of space and functionality relates to how layout, equipment and furnishings contribute to the consumption experience (Harris and Ezeh 2008). Thirdly, there is the dimension of signs, symbols and artefacts. This aspect of the servicescape refers to physical signals which are communicated by way of general meanings, concerning the exchange to consumers (Bitner 1992). Part of this involves quite rudimentary, but still necessary systems of signs, i.e. giving directions, to more complex symbols that can create particular types of impressions (Bitner 1992). These signs and symbols are usually designed to generate customer meaning in relation to what is being provided by the marketer, although it has to be recognised that consumer's subjectivities will also imbue aspects 
of the servicescape with personal meaning (Masberg and Silverman 1996; Rosenbaum and Massiah 2011).

Bitner's paper, however, residing theoretically in environmental psychology, tends to assume that control is largely exercised by the marketer. Consumers as 'organisms' are seen to respond to stimuli from the environment and what takes place either assists, or inhibits, approachlavoidance decisions (Ezeh and Harris 2007). The approach is not driven by socio cultural factors and the methodology is principally about a stimulus-organism-response orientation. Despite this, Bitner's work has spawned a good deal of research and indeed, numerous researchers have moved beyond the original framework to add factors beyond the physical dimension discussed above (Rosenbaum and Massiah 2011). These expanded conceptualisations of the servicescape remain firmly sympathetic with Bitner's agenda, and taken together, provide a useful analytical framework.

In terms of developing the original servicescape, there is firstly, the social dimension (Rosenbaum and Massiah 2011). This extra feature encapsulates customer employee interactions and relationships, a point emphasised by the work of Högström, et al (2010), in their analysis of service quality issues at a winter sports destination. Additionally, more emphasis has been placed by some researchers on the symbolic dimensions, to the extent that it has been proffered as another distinct element of the servicescape (Rosenbaum 2005). Arnould et al (1998) includes the natural dimension as an additional variable, developed when the authors examined a servicescape comprised of white water river rafting operations on the Colorado-Utah border in America. For Arnould et al (1998), the servicescape is divided up into two main elements, that of substantive staging and communicative staging. The former refers to the physical creation of the environment and the latter to the way in which the environment is presented and interpreted, through guides, stories and other forms of communication (Arnould et al 1998). So in the context of the entire servicescape framework, the staging of appropriate customer experiences becomes a central concern (Chronis 2005; Chronis 2008; Högström, et al 2010; Arnould et al 1998). Enter then the idea of experiential marketing, which is viewed here and by others, as being an intrinsic aspect of the total servicescape offering (Chronis 2005).

The notion of experiential marketing was first introduced by Pine and Gilmour (1998). When individuals buy an experience, they pay to spend time enjoying a collection of events that the company is responsible for staging. It is argued that experiential marketing is critical for organisations, particularly those in the heritage industry. Williams (2006) points out that marketing in this industry is always experiential, where a main concern is to extract the quintessence of the product and apply to it intangible, physical and interactive experiences. The process can be viewed then as a procedure of staging, experiencing and then perceiving (Yuan and $\mathrm{Wu}$ 2008). Leighton (2007) gives one such example. A trip to The Galleries of Justice in Nottingham provides visitors with the opportunity to experience a real trial from Victorian times, before being dispatched to the cells where they are greeted by costumed warders and a hangman who welcome them for their stay. In this sense, the research of Chronis (2005) is instructive. This study is an analysis of how Greek consumers extract knowledge and understanding from an examination of their Byzantine history at a heritage site. Chronis argues that heritage marketing needs to be an immersion experience, fostered within a servicescape. This suggests that the 
physical, social and symbolic elements of the framework are to be used imaginatively and collectively by the marketer, in order to create an appropriate consumer experiences. This strongly suggests that the notion of an experiential servicescape is a highly relevant framing device for analysing representations of the Magna Carta.

\section{RESEARCH APPROACH AND METHODS}

The general research method used in this study was based on an interpretative perspective (Goulding 2004). Drawing on qualitative methods, the research sought to obtain visitor perceptions of the Magna Carta exhibition. Marshall and Rossman (2006) and Kvale (1996), indicate that a qualitative approach is usually designed to generate written accounts of experience as data. Consequently, the research was intended to elicit some degree of in- depth understanding. With this type of research, it has to be recognised that the data generated is not intended to produce any universal truths (Hackley 2003). The interviews reported on here are not an antecedent to a quantitative statistical study, although it is recognised that the latter could occur. The intention of the current study was to generate a range of insights into the ways in which the social reality of those who visited the Magna Carta exhibition is constructed. A non probability method of sampling was used where respondents were selected at the convenience of the interviewers (Marshall and Rossman 2006). The approach adopted was based on the suitability of visitors in terms of the theoretical problem being addressed, namely one of exhibition relevance. Here, the approach is to seek the meaning of events and not their causes (Masberg and Silverman 1996).

In order to collect visitor perceptions, semi structured data collection (Matthews and Ross 2010) took place, in the form of a questionnaire, principally composed of open ended questions. The questionnaire was used as an instrument for an interview, with the interaction being limited to questions and answers. Visitor responses were recorded verbatim. Firstly, in order to carry out the research, permission was obtained from the site coordinator of Lincoln Castle. A public holiday was chosen to administer the interviews, in order to guarantee a suitable volume of visitors. It was decided that to be directly situated outside the Magna Carta exhibition was the most logical place to be present, in order to reach the maximum number of people, after they had viewed the document. In total, forty seven interviews were carried out with UK nationals, originating from various parts of the country. Data collection was conducted by a team of three researchers. Prior to this, a pilot questionnaire was prepared and carried out with ten respondents from the general public in order to check if the wording of the subsequent questions was appropriate. The qualitatively inspired questions, numbering eight, asked some wide ranging questions. These included inquiring as to what the respondent considered to be a good heritage experience and what they thought of the current exhibition surroundings for the Magna Carta. Another question related to the nature of the visitors learning experience, whilst others asked about the types of messages the exhibition appeared to be transmitting. Additionally, some background quantitative data on respondents was collected.

In terms of methodology, an aim of this paper, besides investigating and analysing heritage representations, is to demonstrate how a marketing study of the Magna Carta can be informed by a particular approach to teaching and research, namely that of the inquiry led, student as producer perspective (Healey 2005). In terms of conducting 
research and analysis, a mainly qualitative approach has been framed by the student as producer perspective (Healey and Jenkins 2009). This represents an attempt to reengineer the relationship between research and teaching that involves a reappraisal of the affiliation between academics and students. Frequently, students are seen to be passive recipients of the research work of university academics, but significantly, the student of producer perspective alters this dynamic (Neary and Winn 2009).

In a variant of co-creation (Prahalad and Ramaswamy, 2000), undergraduate students become part of the academic project of the university, rather than as simply consumers of knowledge (Neary and Winn 2009). In seeking to implement this approach, this paper created the conditions whereby the framing of research objectives, the preparation of questions, the field work and also the analysis, was conducted jointly by a group of three students and two lecturers, all of whom are listed as authors. The work was module related and part of the undergraduate degree programme of the university. Whilst it may have been traditionally expected that postgraduate students be active researchers in the sense outlined here, this is not usually the case with undergraduates. So, whilst the notion of student as consumer is much discussed in academic circles, less well debated is the extent to which the basis of undergraduate academic life might be rearranged. In line with this, Neary and Hagyard (2010), argue that the resulting partnerships between academics and students should assist in helping to reinvigorate the university in terms of its approach to conducting research.

\section{THE CURRENT LINCOLN MAGNA CARTA EXHIBITION}

By purchasing a ticket to view Lincoln Castle, the visitor is also able to view the 'The First Charters of Liberty' exhibition, which includes not only the Magna Carta, but also the Charta of the Forest. The latter document is important in its own right, being one of only two surviving copies, dating back to 1217. The Charta of the Forest dealt with the rights of the common people to be granted proper subsistence in the forests of the King (Linebaugh 2008). Currently, both these two documents are housed in part of the old prison of the castle. Signs point to the entrance and in the first part of this exhibition artefacts are present from the time of Magna Carta along with display boards of information about life in the $13^{\text {th }}$ century. These boards provide detail about crime and punishment, feudalism and the revolt which resulted in the signing of Magna Carta. Next is an interactive board game which encourages visitors, particularly children, to construct their own version of the hierarchical social order of the $13^{\text {th }}$ century. It is possible in this part of the exhibition, to make a wax 'King's seal'. The second part of the exhibition contains displays and features reflecting the desire to market that Magna Carta not just as a historical document, but one that has relevance for people's lives today. One part of an interactive game for children asks them to identify from illustrations, detainees who are not being fairly treated at the Guantanamo Bay prison camp. There is a 'have your say' section, where visitors can post their own comments on things like the Stop and Search and Anti Terrorist Law. Additionally, information boards tell visitors that there are clauses of the Magna Carta that are embedded in UK law today. Other information panels discuss the relevance of the Magna Carta across the contemporary world. Next, the visitor moves on to the culmination of the exhibition, where the Lincoln Magna Carta is featured alongside the Charta of the Forest. Both documents are contained in temperature monitored, vacuum sealed display cases. 


\section{FINDINGS: THE MAGNA CARTA SERVICESCAPE AND VISITOR EXPERIENCES}

This section of this paper considers the responses of the general tourist to the exhibition outlined above. In terms of this issue of market segmentation, the Lincoln Magna Carta can be said to cover three groups (Ardley and Ardley 2010). One market is schools and a second is represented by America and the various tours that the document has undertaken, to places such as the Ronald Regan Presidential Library. There is additionally, the general tourist market that can be group and individual based. This is a wide ranging segment that includes visitors from abroad and the UK. Covered here are potentially significant differences in terms of age, income, and background, but various studies have shown that common factors exist amongst these variables. These factors include nostalgia, authenticity and the desire for knowledge (Belk1997; Masberg and Silverman 1996; Goulding 2000; Chronis and Hampton 2008).

Firstly, In terms of the background quantitative data obtained from the forty seven general tourist visitors, results show that there were an almost equal number of male and female respondents. In the age ranges, there were seven under twenty one year olds, ten twenty one to thirty year olds, seven thirty one to forty year olds, ten in the forty one to fifty age bracket and finally, thirteen respondents were in the over fifty age range. The majority of visitors had travelled in excess of twenty five miles to view the exhibition. Moving on to the main part of the questionnaire, despite some positive findings emerging such as the fact that virtually all respondents said they had learnt something about the Magna Carta in terms of issues like its links to the American constitution, it is clear that results show three main customer experience problems exist. These are guidance signage, the small, dark inauspicious surroundings of the exhibition and the level of visitor interactivity. All these represent key areas of the experiential servicescape. Firstly, in terms of specific responses, a number of visitors were quite explicit about the inferior quality of lighting. Nearly half of the visitors complained about this feature - encapsulated in five words used by one interviewee - "the exhibition needs better lighting" The following series of short quotes further illustrate this problem.

“It's small cramped and dark........The exhibition could use more lighting......it needs better lighting....It is too dark.... Bit dark and there is a lot to take in...

In terms of the physical environment, lighting is part of the perceived ambient servicescape and represents an object language rather than verbal language Bitner 1992). The absence of effective lighting means that the visitor will pass that much more quickly through the exhibition, without lingering to view the documents or to do the other things normally associated with exhibitions. Visitor action subsequently is very likely being constrained then (Rosenbaum and Massaiah 2011), through this inappropriatel environmental stimuli.

The second major problem relates to the size of the current exhibition. Many visitors wanted to see a much bigger area devoted to the Magna Carta. One respondent, speaking for a significant number, pointed out that what is required "are more open areas and bigger displays.” Other visitors also commented on this problem. Amongst 
these responses were the following. "The display is too small, important documents like this need more exposure"... "What are needed are more open areas."

This issue of open spaces and what occupies space, is an important one, if we consider it in the light of the servicescape. In Bitner's (1992) original work, this aspect forms a hegemonic network of physical items, so the notion of space becomes part of the consumer's evaluative frame, helping them to establish meanings related to what is on offer (Rosenbaum and Massaiah 2011). As Magna Carta appears to be one of the key icons in the United Kingdom today (Culture24.org), then visitors would expect its surroundings to reflect this status. The story being told through the present spatial design of the exhibition presents the visitor with contradictory meanings; here is a significant document, presented in an insignificantly sized space. The current spatial design needs revising then, so as surround Magna Carta with wonder, engendering an aura that its diminutive physical presence alone cannot provide. It is argued that currently, how and where the Magna Carta is displayed within the castle grounds, fails to do justice to such an important document. Rather than generating meanings that identify the document with historic greatness, or the impact of the document on today's laws and culture, it is argued that the opposite occurs, with the manuscript appearing - as a result of its surroundings - to be of little import. As one visitor insightfully commented, "these important documents need more fitting surroundings.”

Another problem identified by one third of surveyed visitors relates to exhibition signage. As Misiura (2006) points out, many heritage organisations use signs for guidance purposes, but this is a feature neglected in the current exhibition. This relates to the third area of the experiential servicescape, namely that of signs symbols and artefacts (Rosenbaum 2005; Bitner 1992). Meaning gets created even by the ordinary, so helping visitors to understand the meaning of the place visited (Rosenbaum and Massiah 2011). Typical comments from visitors included the following,

"The Magna Carta exhibition is not very prominent ....Signpost the exhibition better.... I didn't know where the exhibition was....Provide more signage so people know where it is"

Finally, what visitors also see as important, but a neglected aspect of their visit, is concerned with the poor level of interactivity provided. This aspect of visitor perceptions arose when customers to the site were asked what improvements could be made to the exhibition. Half of all the visitors questioned regarded an increase in interactivity as a necessary enhancement. A typical answer stated that the exhibition organisers must "Make it bigger more interactive and invest money in its development." Other respondents commented that, "More interactivity and audio visual props are essential...... "More interactive displays"......... "Make it more interactive, get visitors involved",...

So it appears that the traditional approach currently adopted, of a static exhibition, does not meet the experiential based needs of these heritage visitors. One visitor to the Magna Carta exhibition gave an example of one type of interactivity, when it was stated that "staff could role play people from the time." Leighton (2007) points out that this type of live interpretation has emerged in recent times as an important way of 
marketing an attraction in an experiential fashion. Actors perform for, or interact with visitors, so as to construe objects and provide the latter with a human element. In these types of situations, high levels of performance are expected and staff must be "in character" (Bryman, 2004). This is the social dimension of the servicescape (Rosenbaum and Massiah 2011), where customer avoidancelapproach decisions are potentially influenced by social-humanistic stimuli, in the form of customer employee interactions. In line with this type of subjective, human projection, another visitor wanted to see “...films' showing what life was like.” More use could be made then of various technologies like multimedia production and 3D projection to include, in the words of another visitor, "videos, headphones, and audio visual development" This aspect represents tangible artefacts of the experiential servicescape, which need to be combined effectively within a well designed spatial setting, along with the social and ambient dimensions of the exhibition.

\section{CONCLUSION: THE SERVICESCAPE AND THE MARKETING OF A MEMORY OF THE WORLD}

Firstly, the significance of the methodological contribution of this paper needs to be stated. In terms of educational and research implications, this paper has employed the student as producer approach. This process is about collaborative research between undergraduate students and lecturers replicating the process of academic research. Using this approach means it could be possible to envisage further academic projects where learning and research is achieved by engagement in similar studies around the marketing of the Magna Carta. Additionally, there exists scope for a range of interdisciplinary studies to be undertaken involving those things which impact on the Magna Carta, like culture, politics law and social theory. As one example, students, with the assistance of tutors as facilitators, and as co creators of research knowledge, could be asked to research the design of the new proposed Magna Carta exhibition centre amongst visitors and to assess the ramifications of their views.

An important issue to consider is one that deals with a very tangible aspect of the servicescape that of the physical goods attached to the visiting experience. Whilst visitors to the Magna Carta were only asked to comment on the exhibition itself, what is likely to add to the general quality of their consuming experience is the availability of related merchandise. As Misiura (2006) points out, it is unusual for customers not to find products available that relate to the historical artefacts they have just seen. For Williams (2006), the purchasing of mementoes of a visit can retail at well above the market value because of the memory attached to the experience. Although there is a small shop in the Castle, what is conspicuously lacking in this outlet is any attempt to sell a range of goods, apart from one book produced by the Cathedral that complements the Magna Carta. Types of merchandise that could be sold in a shop dedicated to the exhibition include Magna Carta pens, jewellery, book markers, books, computer games, ties, coasters, pictures, board games and replicas of the document. This aspect certainly needs to be considered when the new exhibition is put in place.

In terms of the current exhibition, there are a number of experiential servicescape elements that could be improved. These elements also need to be planned for adequately in the new staging of the document. Relating firstly to the physical surroundings (Bitner 1992), is the desire of visitors to see present a range of interactive features in a reimagined Magna Carta display. Early evidence suggests that 
more interactivity is actually being planned for the new exhibition (Lincolnshire Echo 2012). So, a redesigned exhibition could have for example, areas for historic reenactments of the signing of the document or of some of the turbulent events surrounding it. This could be extended to actually involve visitors, so they become characters from the time, as on Brunel's SS Great Britain in Bristol, where visitors can become Victorian passengers for a period of time (Baron 2010). In line with this, visitors to a revamped exhibition could experience a variety of different types of technology, for example touch screens to access Magna Carta games, history, and cocreation experiences. The latter could have visitors writing their own "Magna Carta for a modern world". These last aspects of the experiential servicescape relate to Arnould's et als (1998) notion of communicative staging, where particular interpretations are put forward about the document.

In the second dimension of Bitner's original framework, there is the issue of space. As indicated in the findings section, visitors overwhelmingly thought that this was currently insufficient. Here, useful lessons can be learnt from how other important documents are displayed, like the founding articles of the United States of America. This includes the Declaration of Independence and like the other documents featured, is similar to Magna Carta, an object whose symbolic importance exceeds its physical presence. However, the American documents have been placed in impressive marble cases in order to maximise the impact of their symbolic qualities (Ardley and Voase 2012). All the founding articles are presented together in the Rotunda in Washington DC, which is entered through some impressive iron gates. Then, adding to the awe and facing the visitor, is what looks like an altar, bordered by two United States flags and Corinthian columns, surmounted by eagles. On either side of the columns are large murals, with scenes depicting the founding fathers of the United States. So this type of staging experience suggests the need for a quite dramatic increase in space for Magna Carta, an aspect of "the fitting surroundings" identified by the research. This increase in space will likely engender awe towards the document helping in the process, to augment the symbolic importance of the Magna Carta (Rosenbaum and Massiah 2011).

With the future probability of the Magna Carta being placed in an underground vault (Lincolnshire Echo 2012), the organisers must work to ensure that this is not a confining and claustrophobic experience, where space and openness get compromised. The argument here is that the servicescape of the Magna Carta must tell a story, reminiscent in this respect of the Rotunda. The Magna Carta and its surroundings need to be loaded with a gravitas missing from the current exhibition, so that visitors should be able to answer the question, "What is this place and what does it mean?" Related to these issues of space, design and symbolism, but not yet clear in the plans for the new exhibition, is the physical artefact that will be used to contain the document. It is suggested that improvements need to be made physically to the rather functional case in which the Magna Carta is currently presented, in order for its story to be more openly expressed. Visitors will then recognise not only the authenticity of the document before them, but what it stands for. In the wider reconstructed exhibition, various symbols, i.e. artwork etc, could also be used to situate the Magna Carta within a shared cultural discourse, much like those engendered by the Lincoln Memorial, the Vietnam Veterans Memorial and the Korean War Veterans Memorial. Goldman (et. al. 2001), studied the meanings that visitors attach to these memorial sites in Washington D.C., noting that the presence of 
appropriate symbols prompted in respondents a desire to be engaged in a democratic civil society, whilst also recognising that the memorials represented ideals to try and strive for.

On a more prosaic, yet arguably still important level, the symbolic also includes directional signs (Bitner 1992). Although the current exhibition is right near the main entrance of the castle, visitors complained that it was poorly signposted. This means that signage needs improvement not only immediately outside the exhibition, but also leading up to the castle entrance. Subjectively consumers might assign varieties of meaning to the current lack of signage identified by the research findings. These could range from thinking that the Magna Carta is less of an important document than they thought, to feelings of dissatisfaction with the service provider, even before the document is viewed. Enhancing signage at various strategically selected points outside the castle, could contribute to the anticipation of the visit. As Campbell (1987) argues, the act of consumption begins not with the consumption itself, but with the anticipation of consumption. So with more visitors expected as a result of future Castle improvements (Lincolnshire Echo 2012), attention to signage has to become a priority.

Here, the notion of anticipation probably represents a good point at which to bring to a close this paper. With twelve million pounds due to arrive to undertake major renovation works to Lincoln Castle - to include the Magna Carta exhibition - then anticipation levels are going to be raised about what to expect from a visit. In summing up here, the experiential servicescape framework has been found to be a very useful framework for analysing the Magna Carta exhibition. It is argued that the model has an excellent utility and could be more widely used to analyse other heritage attractions elsewhere. Finally, it is hoped that the proposals outlined here for the re-development of the Magna Carta servicescape could be considered and then implemented in some way, so as to make a contribution to meeting the expectations of visitors, as they experience the Lincoln Magna Carta, 'a mirror and memory of the world.' 


\section{REFERENCES}

Ardley, B. C. and Ardley, M. K. (2010), “The Lincoln Magna Carta: marketing a document that changed the world”, The Marketing Review, Vol. 10 No. 3, pp.287302.

Ardley, B. and Voase, R. (2012), "Magna Carta: Repositioning the secular as sacred", International Journal of Heritage Studies, available at: http://www.tandfonline. com/doi/abs/10.1080/13527258.2012.663780 (accessed $17^{\text {th }}$ April 2012).

Arnould, E.J., Price, L.L. and Tierney, P. (1998), "Communicative Staging of the Wilderness Servicescape”, The Services Industries Journal, Vol. 18 No. 3, pp.90-115.

Barbour, S. and Turnbull, A. (2002), “Dreams, schemes and castles: can entrepreneurial input benefit a heritage tourism resource?” Journal of Research in Marketing and Entrepreneurship, Vol. 4 No. 2, pp. 79-100.

Baron, S., Conway, T. and Warnaby, G. (2010), Relationship marketing: a consumer experience perspective, Sage, London.

Belk, R. W. (1997), Been there, done that, bought the souvenirs: of journeys and boundary crossing, in Brown, S. and Turley, D. (Eds.), Consumer Research; Postcards from the Edge, Routledge, London, pp22-45.

Bennett, N., Bennett, C., Valis, V. and West, M, (2007), The Lincoln Magna Carta, Lincoln Cathedral Publications, Lincoln.

BBC News. (2010, November) "Magna Carta 800th anniversary celebrations begin”, BBC News. Available at: ,http://www.bbc.co.uk/news/uk-11735060. (accessed January 14th 2011).

Bitner, M. J. (1992), "Servicescapes: the impact of physical surroundings on customers and employees”, Journal of Marketing, Vol. 56 No. 2, pp 57-71.

Breay, C. (2002), Magna Carta: manuscripts and myths, The British Library, London.

Bryman, A. (2004), The Dizneyisation of society, Sage, London.

Campbell, C. (1987), The romantic ethic and the spirit of modern consumerism, Blackwell, Oxford.

Chronis, A. (2005), "Our Byzantine heritage: consumption of the past and its experiential benefits”, Journal of Consumer Marketing, Vol. 22 No. 4, pp 213-222.

Chronis, A. (2008), “Co-constructing the Narrative Experience: Staging and Consuming the American Civil War at Gettysburg”, Journal of Marketing Management, Vol. 24 Nos. 1-2, pp 5-27. 
Chronis, A and Hampton, R. D. (2008), “Consuming the authentic Gettysberg: how a tourist landscape becomes an authentic experience", Journal of Consumer Behaviour, Vol. 7 No. 2, pp111-126.

Culture 24 .org, available at: http://www.culture24.org.uk/art362437. ( accessed (April 16th 2012 ).

Danziger, D. and Gillingham, J. (2003), 1215: The year of Magna Carta, Coronet, London.

Ezeh, C. and Harris, L. C. (2007), "Servicescape research: a review and a research agenda”, The Marketing Review, Vol. 7 No. 1, pp59-78.

Goldman, L. T., Chen, Wei Li J., and Larsen, D. L. (2001), "Clicking the icon: exploring the meanings visitors attach to three national capital memorials", Journal of Interpretative Research, Vol 6 No. 1, pp3-29.

Goulding, C. (2000), "The commodification of the past, postmodern pastiche, and the search for authentic experiences at contemporary heritage attractions”, European Journal of Marketing, Vol. 34 No. 7, pp 835-853.

Goulding, C (2004), “Grounded theory, ethnography and phenomenology - a comparative analysis of three qualitative strategies for marketing research", European Journal of Marketing Vol. 39 Nos. 3/4, pp.294-308.

Hackley, C. (2003), Doing research projects in marketing, management, and consumer research, Routledge, London.

Harris, L. C. Ezeh, C. (2008), "Servicescape and loyalty intentions: an empirical investigation”, European Journal of Marketing, Vol. 42 No. 3, pp390-422.

Healey, M. (2005), Linking research and teaching, exploring disciplinary spaces and the role of inquiry-based learning, in. Barnett, R (Ed.), Reshaping the university: new relationships between research, scholarship and teaching, McGraw-Hill/Open University Press.Maidenhead, pp30-42.

Healey, M. and Jenkins, A. (2009), Developing undergraduate research and inquiry, available at: http://wwwheacademy.acuk/assests/York/documents/resources/ publications/DevelopingUndergraduate_finalpdf (accessed march 2011).

Högström, C., Rosner, M. and Gustafsson, A. (2010) "How to create attractive and unique customer experiences: an application of Kano's theory of attractive quality to recreational tourism”, Marketing Intelligence and Planning Vol. 28 No. 4, pp 386402.

Kvale, S. (1996), InterViews, Sage, London.

Leighton, D. (2007), "Step back in time and live the legend: experiential marketing and the heritage Sector", International Journal of Non Profit and Voluntary Sector Marketing, Vol .12, No. 2, pp117-125. 
Lincolnshire Echo (2010),“ $£ 68$ million a year hammer blow to county as Magna Carta centre plan is dropped”, available at: http://www.thisislincolnshire.co.uk/news/16388m-kick-teeth-Magna-Carta-centre-plan-dropped/article-2858157-detail/article.html (accessed November 23rd 2010).

Lincolnshire Echo (2012) “Castle plan wins £12m Lotto cash”, March 29th, p1.

Linebaugh, P. (2008), The Magna Carta Manifesto: liberties and commons for all. University of California Press, London.

Matthews, B. and Ross, L. (2010), Research methods, a practical guide for the social sciences, Pearson Education, Harlow.

Marshall, C. and Rossman, G, (2006), Designing Qualitative Research, Sage, Thousand Oaks.

Masberg, B.A. Silverman, L. H. (1996), "Visitor experiences at heritage sites: a phenomenological approach”, Journal of Travel Research, Vol. 34, No. 4, pp20-25.

McDonald, H. (2011), "Understanding the antecedents to public interest and engagement with heritage”, European Journal of Marketing, Vol. 45 No. 5, pp780804.

Misiura, M. (2006), Heritage Marketing, Elsevier Butterworth Heinemann, Oxford,

Neary, M. and Winn, J, (2009), "The student as producer: reinventing the student experience in higher education”, in, Bell, L., Stevenson, H., and Neary, M. (Eds.), The future of higher education: policy, pedagogy and the student experience, Continuum, London, pp. 192-210.

Neary, M. and Hagyard, A. (2010) "Pedagogy of Excess: An Alternative Political Economy of Student Life” in Molesworth, M., Scullion, R. and Nixon. E (Eds.), The Marketisation of Higher Education and the Student as Consumer, Routledge, Abingdon Oxon, pp 209-223.

Pine, J. B. and Gilmore, J. H. (1998), "Welcome to the experience economy", Harvard Business Review, Vol. 76 No. 4, pp97-105.

Prahalad, C.K. and Ramaswamy, V, (2000), “Co-Opting Customer Competence”, Harvard Business Review, Vol. 78 No 1, pp 79-.87

Rosenbaum, M. S. (2005), "The symbolic servicescape: your kind is welcome here”, Journal of Consumer Behaviour, Vol. 4, No 4, pp257-267.

Rosenbaum, M. S. Massiah, C. (2011), “An expanded servicescape perspective”, Journal of Service Management, Vol. 22 No 4, pp471-490. 
UNESCO.org,(2010) available at: http:/www.unesco.org/ new/en/communicationand-information/flagship-project-activities/memory-of-the-world/homepage/(accessed (April 2012).

Wakefield, K.L. and Blodgett, J. G. (1994), “The Importance of Servicescapes in Leisure Service Settings”, Journal of Services Marketing, Vol. 8 No. 3, pp 66-76.

West, M. (2008), Magna Carta - An Icon for the Twenty First Century? Teaching about human rights and democracy - the Magna Carta as a reference point-Magna Carta workshop report, National Educational Association $\backslash$ National Union of Teachers, London:

Whipps, H. (2008), “How the Magna Carta Changed the World”, available at: http://www.livescience.com/history/080421-hs-magna-carta.html. (accessed December 2010).

Williams, A. (2006), “Tourism and hospitality marketing: fantasy, feeling and fun”, International Journal of Contemporary Hospitality Management, Vol. 18, No. 6, pp482-495.

Yuan, Y. H. and Wu, C. (2008). "Relationships among experiential marketing, experiential value, and customer satisfaction”, Journal of Hospitality \& Tourism Research Vol. 32 No. 3, pp.387-410. 